Bull. Mater. Sci., Vol. 6, No. 1, February 1984, pp. 59-64.

(C) Printed in India.

\title{
Development of pure and doped gamma ferric oxide
}

\author{
M R ANANTHARAMAN, K SESHAN, S N SHRINGI* and \\ H V KEER \\ Department of Chemistry, *Department of Physics, Indian Institute of Technology, Bombay \\ 400076 , India.
}

MS received 7 May 1983; revised 28 December 1983

\begin{abstract}
Optimum conditions and experimental details for the formation of $\gamma-\mathrm{Fe}_{2} \mathrm{O}_{3}$ from goethite have been worked out. In another method, a cheap complexing medium of starch was employed for precipitating acicular ferrous oxalate, which on decomposition in nitrogen and subsequent oxidation yielded acicular $\gamma-\mathrm{Fe}_{2} \mathrm{O}_{3}$. On the basis of thermal decomposition in dry and moist nitrogen, DTA, XRD, GC and thermodynamic arguments, the mechanism of decomposition was elucidated. New materials obtained by doping $\gamma-\mathrm{Fe}_{2} \mathrm{O}_{3}$ with $1-16$ atomic percent magnesium, cobalt, nickel and copper, were synthesised and characterized.
\end{abstract}

Keywords. Magnetic recording materials; gamma ferric oxide; thermal decomposition.

\section{Introduction}

The potential of gamma ferric oxide $\left(\gamma-\mathrm{Fe}_{2} \mathrm{O}_{3}\right)$ as a magnetic tape recording material has provoked a great deal of investigations over the past several years (Smit 1971; Venkatesh Rao et al 1974; Seshan et al 1981b; Anantharaman et al 1981). It can be prepared commercially with the required parameters from synthetic goethite. However the present annual demand of our country $(\sim 25 \mathrm{MT})$ is met mainly through import (Patil 1977). Since most of the literature on this method is patented and/or vaguely known, the first step in the indigenization process involves working out the optimum conditions and experimental details of each step of synthesis on a laboratory scale, before it is taken up on a pilot-plant scale. These have been reported in the present communication. Another preparative method involves thermal decomposition of ferrous oxalate dihydrate in an inert atmosphere to magnetite, followed by careful oxidation to $\gamma-\mathrm{Fe}_{2} \mathrm{O}_{3}$ (Seshan et al 1981a). However, this method involves a costly glycerol medium, which is required to retain acicularity. With a view to economizing the process, a cheap complexing medium of starch has been employed for precipitating acicular ferrous oxalate, almost without loss of quality. Further, the mechanism of thermal decomposition of the oxalate has been reported to involve the existence of $\mathrm{FeO}$ and $\mathrm{H}_{2}$ (Dollimore et al 1963; Bevan and Brown 1966; Venkatesh Rao et al 1974). Experimental evidences, in conjunction with thermodynamic arguments, are being presented to unequivocally elucidate the mechanism. Finally, since $\gamma-\mathrm{Fe}_{2} \mathrm{O}_{3}$, a vacancy-ordered spinel, is thermodynamically unstable with respect to $\alpha-\mathrm{Fe}_{2} \mathrm{O}_{3}$ at ambient temperatures, efforts were made to stabilize the structure and to develop new materials, by doping with small amounts of magnesium, cobalt, nickel and copper in the atomic percent range $1-16$. 


\section{Experimental}

Apart from the conventional solution chemistry precipitation technique, various instrumental methods such as X-ray powder diffraction (XRD), differential thermal analysis (DTA), thermogravimetry (TG), gas chromatography (GC), magnetic hysteresis loop tracing (HLT), initial susceptibility $\left(x_{i}\right)$ and transmission electron microscopy (TEM) were employed to characterize the intermediates at each stage of the reaction process. DTA/TG curves were recorded in air and also in oxygen-free moist and dry nitrogen, using $10 \mathrm{mg}$ of the sample at a heating rate of $5^{\circ} \mathrm{C} / \mathrm{min}$ and a gas flow rate of $150 \mathrm{ml} / \mathrm{min}$. The XRD of the samples were carried out in a Philips X-ray diffractometer

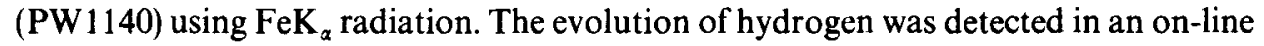
gas-chromatograph (AIMIL-NCL Dual Column gas chromatograph Mk II) using molecular sieve $13 \times$ column in a carrier gas atmosphere of oxygen-free nitrogen. The magnetic properties were measured on a hysteresis loop tracer and initial susceptibility unit (Likhite et al 1965; Radhakrishnamurty and Sahasrabudhe 1965). The shape and size of the particles were determined from transmission electron micrographs taken on a Philips electron microscope (EM301).

\subsection{Synthesis of goethite}

Goethite was synthesized from a solution of $\mathrm{FeSO}_{4} \cdot 7 \mathrm{H}_{2} \mathrm{O}$ (Camras 1954) and scrap iron containing a seed solution of $\alpha-\mathrm{FeOOH}$ aided by constant aeration (Camras 1954) for several hours.

\subsection{Synthesis of ferrous oxalate}

It is well-known that the aqueous medium is unsuitable for the precipitation of $\mathrm{FeC}_{2} \mathrm{O}_{4} \cdot 2 \mathrm{H}_{2} \mathrm{O}$ (FOD), as it yields only spherical particles (Seshan et al 1981a). Literature reports (Berkowitz and Schuele 1968; Seshan 1981b) show employment of the costly glycerol as the complexing medium to precipitate acicular FOD. After trying several media, it has been found that a saturated solution of starch and water could be employed to obtain acicular crystals.

\subsection{Synthesis of mixed oxalates}

The starting materials for the synthesis of doped gamma ferric oxide were mixed oxalates of iron and the dopant $(\mathrm{Mg} / \mathrm{Co} / \mathrm{Ni} / \mathrm{Cu})$, which was co-precipitated from a solution of the corresponding sulphates in required proportions, using oxalic acid. The medium for precipitation was starch and water in order to yield needle-like crystals of the mixed oxalate. The dopant concentration was varied between 1 and 16 atomic percent.

\section{Results and discussion}

\subsection{Formation of maghemite from synthetic goethite}

It is well-known that the preparation of synthetic goethite $(\alpha-\mathrm{FeOOH})$ follows the sequence

Goethite $\rightarrow$ Hematite $\rightarrow$ Magnetite $\rightarrow$ Maghemite. 
Analysis of the XRD pattern showed 3 principal $d_{h k l}$ lines viz., $4 \cdot 179 \AA, 2 \cdot 440 \AA$ and $2.684 \AA$ corresponding to 100,72 and $45 I / I_{0}$ respectively. These are in good agreement with the reported ASTM data (1966). DTA of these samples exhibited an endothermic peak at $250^{\circ} \mathrm{C}$, with a corresponding mass loss of $10.3 \%$ (from TG) associated with the formation of $\mathrm{Fe}_{2} \mathrm{O}_{3}$. Therefore, dehydration of goethite was carried out isothermally at $250^{\circ} \mathrm{C}$ for a sufficient length of time $(30 \mathrm{~min})$ to yield $\alpha-\mathrm{Fe}_{2} \mathrm{O}_{3}$. The XRD pattern of these samples on analysis indicated the presence of 3 principal $d_{h k l}$ lines, viz., $2.69,1.69$ and $2.51 \AA$ corresponding to 76,38 and $100 I / I_{0}$ respectively. These are in good conformity with the reported ASTM data (1966).

Further, both $\alpha-\mathrm{FeOOH}$ and $\gamma-\mathrm{Fe}_{2} \mathrm{O}_{3}$ were found to be acicular (length/breadth $\simeq 10$ ) from TEM micrographs (cf figure 1). It has been reported (Camras 1954) that reduction of $\alpha-\mathrm{Fe}_{2} \mathrm{O}_{3}$ at about $400^{\circ} \mathrm{C}$ yields $\mathrm{Fe}_{3} \mathrm{O}_{4}$. Therefore, $\alpha-\mathrm{Fe}_{2} \mathrm{O}_{3}$ was isothermally reduced at $350^{\circ}, 370^{\circ}$ and $400^{\circ} \mathrm{C}$ respectively with hydrogen for $45 \mathrm{~min}$. It was found that at $370^{\circ} \mathrm{C}$, quantitative reduction to black, acicular $\mathrm{Fe}_{3} \mathrm{O}_{4}$ takes place. The experimentally observed lattice constant $(a=8 \cdot 36 \AA)$ agreed favourably with the reported ASTM value of $8.396 \AA$ (1966). Further, the magnetization value of $85 \mathrm{emu} / \mathrm{gm}$ was in excellent agreement with the expected one ( $90 \mathrm{emu} / \mathrm{gm})$.

The oxidation of $\mathrm{Fe}_{3} \mathrm{O}_{4}$ to $\gamma-\mathrm{Fe}_{2} \mathrm{O}_{3}$ is generally carried out in air containing water vapour with $P_{\mathrm{H}_{2} \mathrm{O}} \simeq 30$ torr (David and Welch 1956). To find the optimum conditions, DTA and TG of $\mathrm{Fe}_{3} \mathrm{O}_{4}$ were carried out in a current of moist air $\left(P_{\mathrm{H}_{2} \mathrm{O}} \simeq 28\right.$ torr $)$ which

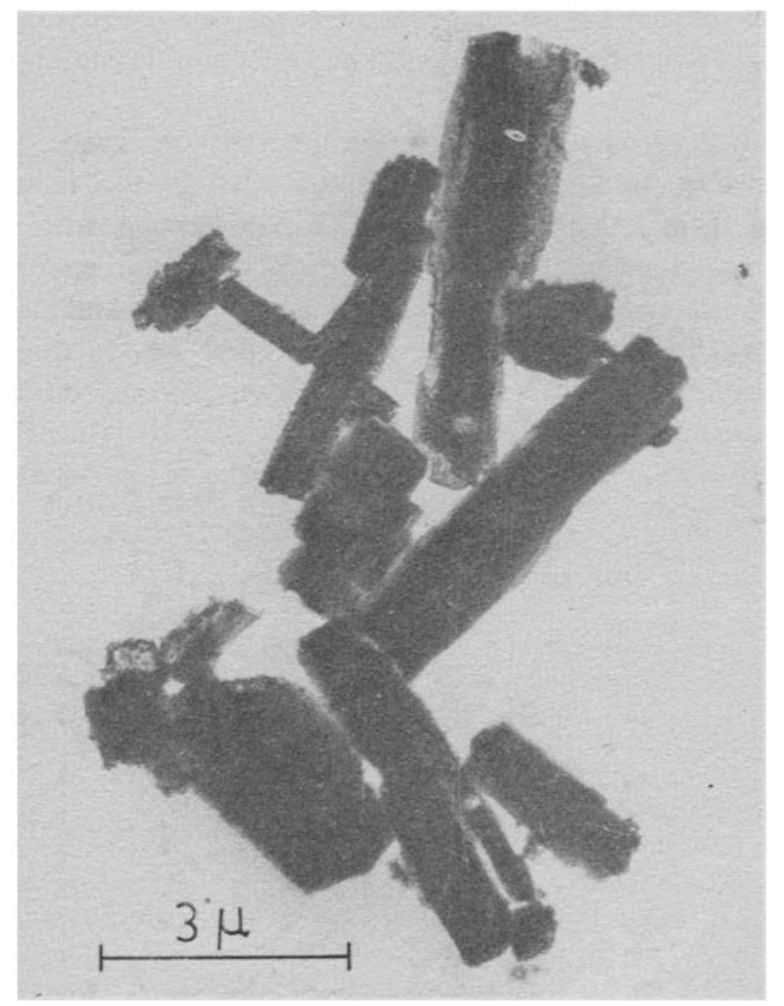

Figure 1. TEM photograph of acicular $\gamma-\mathrm{Fe}_{2} \mathrm{O}_{3}$. 
indicated an exothermic peak at $250^{\circ} \mathrm{C}$, accompanied by a gain in mass of $3.2 \%$ corresponding to the formation of $\mathrm{Fe}_{2} \mathrm{O}_{3}$. Therefore the oxidation process was isothermally carried out in moist air. $\left(P_{\mathrm{H}_{2} \mathrm{O}} \simeq 28\right.$ torr $)$ at $150^{\circ}, 180^{\circ}, 210^{\circ}$ and $250^{\circ} \mathrm{C}$ respectively for $30 \mathrm{~min}$ each. At a minimum temperature of $180^{\circ} \mathrm{C}, \gamma-\mathrm{Fe}_{2} \mathrm{O}_{3}(a$ $=8.34 \AA$ ) with required properties (magnetization $=74 \mathrm{emu} / \mathrm{gm}$; coercive field $=290$ Oe) was formed.

\subsection{Mechanism of thermal decomposition of ferrous oxalate dihydrate under nitrogen atmosphere}

There have been several reports in the literature about the thermal decomposition of FOD in inert-mainly nitrogen atmosphere (Bevan and Brown 1966; Venkatesh Rao et al 1974; Seshan et al 1981a). The accepted mechanism of decomposition has been

$$
\begin{array}{ll}
\mathrm{FeC}_{2} \mathrm{O}_{4}: 2 \mathrm{H}_{2} \mathrm{O} & =\mathrm{FeC}_{2} \mathrm{O}_{4}+2 \mathrm{H}_{2} \mathrm{O} \\
\mathrm{FeC}_{2} \mathrm{O}_{4} & =\mathrm{FeO}+\mathrm{CO}+\mathrm{CO}_{2} \\
3 \mathrm{FeO}+\mathrm{H}_{2} \mathrm{O} & =\mathrm{Fe}_{3} \mathrm{O}_{4}+\mathrm{H}_{2}
\end{array}
$$

This, however, raises a few questions:

(i) Has the existence of intermediate $\mathrm{FeO}$ been experimentally established? $\mathrm{FeO}$ has been known to be thermodynamically unstable below $575^{\circ} \mathrm{C}$ and disproportionates according to

$$
4 \mathrm{FeO}=\mathrm{Fe}_{3} \mathrm{O}_{4}+\mathrm{Fe}
$$

(ii) Does the presence or absence of moisture have any effect on the stability of $\mathrm{FeO}$, if at all formed?

(iii) Has the evolution of hydrogen gas been experimentally observed?

In an attempt to prove the existence of $\mathrm{FeO}$ at $710 \mathrm{~K}$-the temperature of decomposition inferred from DTA/TG studies-isothermal decomposition of ferrous oxalate dihydrate was carried out in dry as well as in moist oxygen free, ultra high pure nitrogen. The decomposition products were analysed using XRD, $G C$ and magnetization measurements. These analyses confirmed the formation of $\mathrm{Fe}_{3} \mathrm{O}_{4}$ during the decomposition under moist nitrogen atmospheres. The decomposition products obtained

\begin{tabular}{|c|c|c|c|c|c|c|c|}
\hline \multicolumn{4}{|c|}{ In dry nitrogen } & \multicolumn{4}{|c|}{ In nitrogen containing water vapour } \\
\hline$d(\mathrm{~A})$ & $I / I_{0}$ & $h k l$ & Phase & $d(\AA)$ & $I / I_{0}$ & $h k l$ & Phase \\
\hline 3.742 & 44 & 210 & $\mathrm{Fe}_{2} \mathrm{O}_{3}$ & $4 \cdot 833$ & 8 & 111 & $\mathrm{Fe}_{3} \mathrm{O}_{4}$ \\
\hline 2.975 & 3 & 220 & $\mathrm{Fe}_{3} \mathrm{O}_{4}$ & $2 \cdot 960$ & 26 & 220 & $\mathrm{Fe}_{3} \mathrm{O}_{4}$ \\
\hline $2 \cdot 525$ & 7 & 311 & $\mathrm{Fe}_{3} \mathrm{O}_{4}$ & $2 \cdot 529$ & 100 & 311 & $\mathrm{Fe}_{3} \mathrm{O}_{4}$ \\
\hline $2 \cdot 489$ & 2 & 111 & $\mathrm{FeO}$ & $2 \cdot 410$ & 5 & 222 & $\mathrm{Fe}_{3} \mathrm{O}_{4}$ \\
\hline $2 \cdot 234$ & 8 & 321 & $\mathrm{Fe}_{2} \mathrm{O}_{3}$ & $2 \cdot 098$ & 23 & 400 & $\mathrm{Fe}_{3} \mathrm{O}_{4}$ \\
\hline $2 \cdot 141$ & 4 & 200 & $\mathrm{FeO}$ & 1.710 & 5 & 422 & $\mathrm{Fe}_{3} \mathrm{O}_{4}$ \\
\hline $1 \cdot 513$ & 5 & 220 & $\mathrm{FeO}$ & 1.615 & 23 & 511 & $\mathrm{Fe}_{3} \mathrm{O}_{4}$ \\
\hline 1.482 & 22 & 440 & $\mathrm{Fe}_{2} \mathrm{O}_{3}$ & & & & \\
\hline
\end{tabular}
under dry conditions were highly reactive and to inhibit oxidation of the products, they were quickly transferred to molten wax. X-ray analysis of the above products showed

Table 1. Products of decomposition of $\mathrm{FeC}_{2} \mathrm{O}_{4} \cdot 2 \mathrm{H}_{2} \mathrm{O}$. 
the presence of $\mathrm{FeO}$ lines along with those of $\mathrm{Fe}_{3} \mathrm{O}_{4}$ and $\mathrm{Fe}_{2} \mathrm{O}_{3}$. This confirmed the formation of $\mathrm{FeO}$ during the course of reaction. The details of the XRD findings are reproduced in table 1 as reported by Anantharaman et al (1982). Further, on line GC studies conducted for the isothermal decomposition of ferrous oxalate dihydrate indicated the liberation of hydrogen as required by the suggested mechanism.

Since the standard free energy change for the reaction $\mathrm{Fe}+\mathrm{H}_{2} \mathrm{O}=\mathrm{FeO}+\mathrm{H}_{2}$ is negative $(\sim-2.2 \mathrm{kcal} / \mathrm{mol})$ at $710 \mathrm{~K}$, it is probable that, in the presence of moisture, iron metal resulting from the disproportionation reaction, $4 \mathrm{FeO}=\mathrm{Fe}_{3} \mathrm{O}_{4}+\mathrm{Fe}$, will get oxidised to $\mathrm{FeO}$. A combination of these two reactions gives

$$
3 \mathrm{FeO}+\mathrm{H}_{2} \mathrm{O}=\mathrm{Fe}_{3} \mathrm{O}_{4}+\mathrm{H}_{2}
$$

thus it appears that, in the absence of moisture, $1 \mathrm{~mol}$ of $\mathrm{Fe}_{3} \mathrm{O}_{4}$ is produced from 4 moles of $\mathrm{FeO}$, while in the presence of moisture, only 3 moles are required to yield the same quantity of $\mathrm{Fe}_{3} \mathrm{O}_{4}$. Therefore, the presence of moisture increases the yield of magnetite $-\mathbf{a}$ fact recognized empirically several years ago by David and Welch (1956).

\subsection{Synthesis of doped maghemite}

DTA of all the mixed oxalates in moist nitrogen $\left(P_{\mathrm{H}_{2} \mathrm{O}} \simeq 35\right.$ torr) showed two characteristic endothermic peaks, corresponding to dehydration $(\sim 495 \mathrm{~K})$ and decomposition $(\sim 710 \mathrm{~K})$ respectively. Accordingly, the mixed oxalates were decomposed around $710 \mathrm{~K}$ for $30 \mathrm{~min}$, followed by oxidation at $475 \mathrm{~K}$ in a stream of air. All the compositions were found to be monophasic cubic spinels, with practically no change in lattice parameter from that of pure maghemite. The magnetic properties of the doped compositions have been reported recently by Anantharaman et al (1982) and are reproduced in table 2 . Indications are that only cobalt-doped $\gamma-\mathrm{Fe}_{2} \mathrm{O}_{3}$ has high $\sigma_{s}$ and $H_{C}$ values and, therefore potentially useful in applications.

\subsection{Thermal stability of doped maghemite}

It is well-known that $\gamma-\mathrm{Fe}_{2} \mathrm{O}_{3}$ has a defect spinel structure $\mathrm{Fe}^{3+}\left[\mathrm{Fe}_{5 / 3}^{3+} \square 1 / 3\right] \mathrm{O}_{4}^{2-}$ where the vacancies are concentrated at the octahedral sites. The structure is unstable and converts irreversibly to rhombohedral $\alpha-\mathrm{Fe}_{2} \mathrm{O}_{3}$ around $400^{\circ} \mathrm{C}$. Thus it may be worthwhile to assess the effect of dopants on the thermal stability of $\gamma-\mathrm{Fe}_{2} \mathrm{O}_{3}$ structure.

Table 2. Magnetic properties of doped $\gamma-\mathrm{Fe}_{2} \mathrm{O}_{3}$.

\begin{tabular}{|c|c|c|c|c|c|c|c|c|}
\hline \multirow[b]{2}{*}{$\begin{array}{l}\text { Dopant } \\
\text { (atomic }\end{array}$} & \multicolumn{2}{|c|}{ Cobalt } & \multicolumn{2}{|c|}{ Nickel } & \multicolumn{2}{|c|}{ Magnesium } & \multicolumn{2}{|c|}{ Copper } \\
\hline & $\sigma_{\mathrm{o}} \sigma_{s}(\mathrm{emu} / \mathrm{g})$ & $\begin{array}{l}H_{c} \\
(\mathrm{Oe})\end{array}$ & $\begin{array}{c}\sigma_{s} \\
(\mathrm{emu} / \mathrm{g})\end{array}$ & $\begin{array}{c}H_{\mathrm{c}} \\
(\mathrm{Oe})\end{array}$ & $\underset{(\mathrm{emu} / \mathrm{g})}{\sigma_{s}}$ & $\begin{array}{c}H_{c} \\
(\mathrm{Oe})\end{array}$ & $\begin{array}{c}\sigma_{s} \\
(\mathrm{emu} / \mathrm{g})\end{array}$ & $\begin{array}{l}H_{c} \\
(\mathrm{Oe})\end{array}$ \\
\hline 1 & 94 & 270 & 83 & 225 & 89 & 320 & 76 & 300 \\
\hline 2 & 71 & 382 & 86 & 270 & 100 & 270 & 80 & 270 \\
\hline 4 & 74 & 371 & 78 & 250 & 76 & 230 & 94 & 320 \\
\hline 6 & 72 & 562 & 75 & 230 & 91 & 270 & 80 & 250 \\
\hline 8 & 90 & 810 & 73 & 230 & 81 & 210 & 77 & 250 \\
\hline 10 & 93 & 675 & 81 & 250 & 80 & 200 & $69^{*}$ & 230 \\
\hline 16 & 81 & 675 & 74 & 250 & 86 & 200 & $55^{*}$ & 250 \\
\hline
\end{tabular}

*Unsaturated 
The dopant ions may occupy A or B sites depending on their site preference, details of heat treatment etc.

DTA studies did not provide fruitful results, presumably due to very small energy change associated with the $\gamma \rightarrow \alpha$ conversion process. Since the $\gamma$-phase is ferrimagnetic and the $\alpha$-phase antiferromagnetic, initial susceptibility $\left(x_{i}\right)$ measurements were employed to serve as a tool for distinguishing between the magnetic (ferrimagnetic) and non-magnetic (antiferromagnetic) state of samples. The onset of $\gamma \rightarrow \alpha$ transition was expected to be accompanied by a rapid decrease in $x_{i}$ value which subsequently should reduce to zero.

While pure $\gamma-\mathrm{Fe}_{2} \mathrm{O}_{3}$ showed a transition beginning around $275^{\circ} \mathrm{C}$, the doped samples consistently showed a higher conversion temperature $\left(\geqslant 300^{\circ} \mathrm{C}\right)$ indicating greater thermal stability. The stability thus achieved could have been partly due to increased potential energy determined by the valence states of the dopant and the host $\mathrm{Fe}^{3+}$ ions. To check the microstructural changes thus introduced, preliminary Mössbauer spectra were recorded with a $\mathrm{Fe}^{57}$ source at room temperature. Hyperfine fields, isomer shifts and quadrupole splittings were calculated. The values of hyperfine fields in these samples did not differ from that of pure $\gamma-\mathrm{Fe}_{2} \mathrm{O}_{3}(505 \pm 20 \mathrm{kOe})$ indicating that the dopant concentrations were too low to introduce discernible variations in the magnetic field. The hyperfine pattern of the Mössbauer spectra was characteristic of a single magnetic field, since the effective magnetic field was found to be the same for both A and B sites. The isomer shifts also remained unaffected with doping suggesting that $\mathrm{Fe}^{3+}$ ions do not change their valence state.

\section{Acknowledgement}

The authors gratefully acknowledge the financial assistance given by the Indian National Science Academy and the CSIR.

\section{References}

Anantharaman M R, Seshan K, Chakrabarty D K and Keer H V 1981 Bull. Mater. Sci. 3275

Anantharaman M R, Shewale S S, Seshan K and Keer H V 1982 Indian J. Chem. A21 214

Berkowitz A E and Schuele W J 1968 J. Appl. Phys. 391261

Bevan S C and Brown R A 1966 J. Inorg. Nucl. Chem. 28387

Camras M 1954 US Pat. 2694656 (to Armour Research Foundation of Illinois Institute of Technology)

David I and Welch A J E 1956 Trans. Faraday Soc. 521642

Dollimore D, Griffiths D L and Nicholson D 1963 J. Chem. Soc. 42617

Inorganic powder diffraction file 1966 ASTM data card no. 29-7130

Inorganic powder diffraction file 1966 ASTM data card no. 11-614

Inorganic powder diffraction file 1966 ASTM data card no. 24-81

Likhite S D, Radhakrishnamoorthy C and Sahasrabudhe P W 1965 Rev. Sci. Instrum. 361558

Patil S G 1977 Electronics Information and Planning 4979

Seshan K, Anantharaman M R, Venkatesh Rao, Shashimohan A L, Keer H V and Chakrabarty D K 1981 a

Bull. Mater. Sci. 3201

Seshan K, Chakrabarty D K and Biswas A B 1981b Phys. Status Solidi. 63A K123

Smit J 1971 Magnetic properties of materials (New York: McGraw Hill Inc)

Venkatesh Rao, Shashimohan A L and Biswas A B 1974 J. Mater. Sci. 9430

Radhakrishnamurty C and Sahasrabudhe P W 1965 J. Indian Geophys. Union. 25 